\title{
Práticas corporais ante a ética nos discursos
}

\author{
CARMO JÚNIOR, Wilson do ${ }^{l}$
}

\section{Resumo}

As práticas corporais no mundo contemporâneo surgem como a mais expressiva forma de cultura da saúde e beleza. A cultura do estar em forma chega sem avisar, uma espécie de necessidade que virou moda. Vimos que a cultura dos homens sempre elogiou essa necessidade vital dos exercícios, das práticas corporais, da ginástica. Aquelas atividades orgânicas que no princípio supunham uma ética natural e de sobrevivência, hoje se rotula numa nomenclatura prática com se fossem invenção de última hora para salvar os homens da indolência, da impostura do conforto. Para administrar essa competência inusitada, trocamos a ética natural pela ética do discurso. Deixamos de ser corporal e práticos e nos tornamos verbal e teóricos. O retorno ao ser corporal e motor requer uma ética ante o discurso.

Palavras-Chaves: Práticas corporais; saúde; beleza.

\section{As primeiras lições}

Não parece novidade a presença de um ser humano interessất em preservar sua saúde e sua qualidade de vida no mundo contemporâneo, sobretude nos dias de hoje. Uma reflexão mesmo que tímida demonstra estar o homem, interessado na preservação da saúde, na qualidade de vida, sobretudo na própria vida. O discurso sobre o corpo humano na cultura parece ter ultrapassado o sentido isolado, dito na sua concepção biológica e na sua condição de carne ou substância, para requerer o sentido de entidade, na qual repousam outros sentidos ao corpo é dado alcançando o simbólico também como elemento da totalidade do homem. Afirmar com categoria que o corpo e o homem são entidades conexas inspira as mais enfáticas estruturas lógicas dos sistemas filosóficos, porém confirmar essa lógica, não parece tarefa fácil. Essa questão se torna mais complexa quando o fenômeno corporal se impõe além da metafísica ou de qual'quer

${ }^{1}$ Prof. Ms Departamento de Educação Física - IB - UNESp - Rio Claro - SP

Revista Kinesis, Santa Maria, $N^{\circ}$ Especial, p. 52-154, nov. 2001 
forma de ciência, arte, linguagem, ou religião para atingir a espécie humana enquanto capacidade de se ver em luta pela sobrevivência. Assim nasce o contexto das práticas corporais em toda sua complexidade e cultura, focando o tema para questões de motricidade, educação física, ginástica, esporte, dança e outras infinitas categorias de expressão regentes da corporeidade do homem.

Tem-se a impressão de que nesse momento da cultura o verbo se fez corpo, e ambos tornaram-se aliados na busca de uma concepção mais autêntica que possa assegurar o ato motor humano com fenômeno de potência da vida. Muito antes do espectro biológico do sentido de sobrevivência na qual a espécie humana sempre esteve interessada, o corpo e sua motricidade geral surgem como virtude e nobreza, necessidade de sobrevivência e atividade cultural. Aquela atividade orgânica primitiva, o uso do corpo no mundo natural, a ascensão do organismo sadio e belo, veloz e forte, sobretudo na espécie humana, parece ter sido a primeira ética, o sentido literal e figurado dessa busca pela vida. Mover o corpo tem-se tornado afirmar-se no mundo, além do ideal o necessário, é esse sentido que as práticas corporais, mais precisamente, como que cada sociedade faz uso do corpo humano e sua motricidade geral, enquanto entidade, é que pode justificar a natureza e o conceito mais original da ética para a vida, saúde e beleza.

Não menos importante, a questão do corpo como entidade absoluta do ser, impõe uma conduta estética imperiosa que faz do ser humano um ser corporal. Essa incrível e reveladora parceria entre saúde, beleza, prazer, auto-estima, entre outras vertentes ou abordagens acerca da corporeidade humana, nos reporta para uma antropologia além orgânica, uma história além da leitura, uma psicologia além da alma, uma filosofia além da metafísica, uma educação física além da nomenclatura. No rigor da cultura corporal no homem, o exercício orgânico sempre transcendeu qualquer esboço intelectual, teórico ou prático, pois o organismo, reconhecido como fundamento da identidade pessoal foi quem garantiu a sobrevivência na luta pela vida. Não menos natural e espetacular, no corpo próprio repousa a existência quase única, a validez ontológica. É aí que se instala o ser. Fora dele nossa presença no mundo não faz sentido algum.

No início, no começo dos tempos, o mover humano se pronunciava da expressão mais viva do ser, uma amalgama motora e gestual cuja finalidade era a comunicação, se fazia em palavras. Não por acaso, mas pela necessidade de expressão, desde o início até nossos tempos todo verbo dito por algum Deus ou pela natureza exprime coisas, sentimentos, ideias, leis, fenômenos...Afirma Starobinski “...na grande festa dos primeiros tempos, toda palavra era celebrante e trazia em si própria a substância do real indicado". Prestigiar o corpo, muito antes dos gregos, a espécie humana já se pronunciava como conhecedor de um corpo como indistinto do universo. Esse todo ontológico habitava as impressões visuais e táteis, de maneira a dar ao homem uma pluralidade de sentidos, o reconhecimento tácito de que a consciência já existia enquanto ato motor que começa e termina no corpo. Isto porque no ỉnexplicável ser do homem, o corpo fora utensílio, o primeiro instrumento, interventor perthanente nas ocupações de espaços no mundo do fazer, e se fazíamos como corpo, fazíamos também como consciência, só depois, muito depois como máquina.

A intenção grega de inovar as formas de pensamento acerca do homem corporal não excluiu a dinâmica prática tanto moral quanto orgânica. O que antes na paidéia supunha à educação uma condição natural e universal da comunidade humana, só tardiamente apareceu como obra a ser cumprida. Na tradição humana de vestir-se de cultura há em Homero os vestígios da ação educativa, visto como processo de condução da formação humana a evidência inseparável entre estética e ética, característica do pensamento grego primitivo. A partir daí o triunfo da razão. 
O indicativo da cultura educativa como procedimento didático na esfera do culto ao corpo, escapou do sentido de entidade pela pressão intelectual exercida pelo cérebro executivo, uma certa repugnância ao primitivo do homem. No lugar dos deuses o pensador, no lugar do poeta o calculador, no lugar da ética a convenção, no lugar da estética a moda. Tudo o quanto foi vivido, é agora pensado. Nessa quimera escolástica estamos tentando recompor um glossário ético-moral sobre as coisas corporais, como coisas do poder, desenvolvendo como profissional conteúdos das práticas corporais, não como executor-transformador, mas como aquele que fala, mas não faz. Como pano de fundo, pensadores do corpo, e na superfície os proprietários do conhecimento sobre o corpo, funda-se o a priori corporal do conhecimento. Ora, se praticamos exercícios ou fazemos ginástica é porque estamos incessantemente exercendo o direito e não o dever de existir, isso posto não usamos o corpo como um ato expropriado da razão ou qualquer dicotomia pré-fabricada. A unidade do pensamento e do organismo não repousa num casamento tardio. Assim, "sistema de potências motrizes ou de potências perceptivas, revela o ponto de partida de tudo o que sou, o corpo não é objeto para nenhum eu penso, é um conjunto de significações vividas que avança par uma harmonia sem precedente" (Merleu-Ponty, 1963). Portanto, qualquer tentativa de endereçamento ético para exercer o direito de propriedade sobre o uso do corpo humano nas práticas corporais, implica numa desqualificação do sujeito.

Entendamos aqui a força de um conceito e a estrutura filosófica que o pontifica. Sabemos e conhecemos um conteúdo chamado educação física. Um fenômeno cultural mais que uma instituição. Seria mais interessante demonstrar a significação e a expressão histórica onde se fundamenta o ato de educar fisicamente, repensar esse projeto no âmbito da cultura do que firmar, ante a duvidosa versão do conhecimento da área, como reportagem ética sobre profissão e o profissional que dela deriva.

O discurso sobre as práticas corporais, sobretudo sobre o uso do corpo enquanto entidade, não parece ser exclusividade de alguma instituição, legião, escola, área de conhecimento. Mesmo porque vimos como no início da formação da cultura ocidental, na sua densidade especulativa, na apaixonada crítica platônica, o ser corporal se desprende de si mesmo, conseguiu limitar o valor da subjetividade poética em nome da objetividade lógica. Se no primeiro momento da espécie humana, nasceu a virtude moral absoluta da sobrevivência enquanto necessidade, aos poucos a perdemos em nome da moral relativa das ideias e das matérias. Assim como, no mesmo sentido de sobrevivência, a ética rigorosa que gerenciava o desejo de manutenção daquela moral, parece ter sido substituída pela ética móvel das constante variáveis metafísicas e das religiões idealizadas.

Cada ser humano é seu infinito corporal e motor, diria um primata se pudesse falar.

\section{Ética: obrigação moral}

A lembrança do fruto proibido parece ser o que há de mais recôndito na memória de cada um de nós, como na de todos aqueles que estão prestes a extrapolar um desejo, uma necessidade, uma cobiça, ou qualquer outro pecado compreendido na cultura dos homens. Vimos uma certa obediência natural, se não, de consciência, quando um estatuto qualquer, determinado por alguma instituição da sobrevivência moral, impõe quase que intuitivamente no que concerne ao certo ou

Revista Kinesis, Santa Maria, $N^{o}$ Especial, p. 54-154, nov. 2001 
errado, sagrado ou profano, verdadeiro ou falso das coisas corporais. Parece também que aprendemos muito rapidamente acatar o saber moral vindo de pais e mestres na conduta do bem. Essa força propulsora do bem humano se estrutura numa espécie de hierarquia sábia, e se desdobram naturalmente como um alicerce invisível e disciplinado por uma consciência natural. Assim como as células de um organismo, unidas por vínculos invisíveis, subordinam-se umas as outras e obedecem a leis necessárias, integrando-se para o bem do todo orgânico. Essa lição de Bergson (1978), demonstra um hábito numa inexplicável tarefa de cooperação de conduta numa ordem impessoal, que pressiona a vontade isolada em nome de algo supremo.

A força que uma obrigação enfoca o dever ser, que extrai de todas as demais, é antes comparável intento da vida, do micro ao macrocosmos, do paramécio ao mamífero superior sempre exprimem, cada qual na sua graduação, o todo de sua vitalidade. Assim, em qualquer sociedade humana impera uma comunidade de seres livres, mesmo que acuados pelas obrigações, impõem-se sutilmente a necessidade vital a ordem inflexível dos fenômenos da vida. A reflexão filosófica pode inspirar seres humanos a se entreter com essa ética invisível, porém não pode destruí-la. Assim como não podemos ver a doença à luz do dia, não podemos avaliar o que há de anti-ético na posturas dos homens que sua fachada exibe. Diz Bergson (1978), "o mal se oculta tão bem, o segredo é tão universalmente conservado que, cada um, no caso, é enganado por todos: por mais severamente que pretendemos julgar os demais homens, no fundo os acreditamos melhores do que nós. Nessa feliz ilusão repousa boa parte da vida social.". O que é lamentável é que essa ilusão sempre é alimentada por alguma lei precedente e que de alguma maneira fará perpetuar essa diferença.

No mundo natural há uma ética implacável. A competição pela vida indica o primeiro passo a ser dados para que a espécie sobreviva, para se acasalar, alimentar, ou dominar seus territórios, qualquer vida selvagem impõem a ética natural, parece ser o homem o único ser vivo fraudador dessa forma de comportamento. A instituição da razão impera sobre as outras formas de pensamento. $\mathrm{Na}$ vida selvagem, a vergonha de um delito cometido, a ética natural lhe determina a sentença fatal: a morte. Ora, se nas comunidades primitivas, onde reina um determinismo sagrado, não sabemos sequer como compreender a vida daquelas criaturas, como podemos inventar uma ética para cultivarmos nossa própria vida e conduta? A ética que somos, diria qualquer estudioso da vida selvagem, parece estar intrincada entre nomenclaturas intelectuais, que possam fazer lucros e exercer o mais puro egocentrismo. O Olhar original de qualquer entidade primitiva consegue enxergar uma ética primitiva, assim deveríamos ver - a ética como liturgia. Com vê Leenhardt (1967), Lévy-Bruhl (1966), Lévy-Strauşs (1976), Cassirer (1976), cada qual com seu olhar descritivo, revela o intuito humano. Assim, antes da lógica, a ética é crença que fez e faz estudiosos de seres humanos na sua totalidâđé ontológica lembrarem-se das leis de dos Lubas (comunidade tribal) citado por Dougkts (1966) de causalidade vital: que um humano (vivo ou morto) pode reforçar diretamente ou diminuir o ser (ou força) de outro ser humano; que a força vital de um homem pode influenciar diretamente forças de seres inferiores, independente de categorias animal, vegetal, mineral; que o ser racional (espírito, humano vivo ou morto) pode agir indiretamente sobre outro, comunicando sua influencia vital a uma força intermediária inferior.

A rigor, os homens, céticos a esse comportamento, ou não, os efeitos deletérios resultantes dos males humanos em torno de sua comunidade se espalham na medida da modificação dos comportamentos, daí se transformam-se em novos valores, e por fim a acomodação ética. Os homens esperam a doença para inventarem o remédio. $O$ mal anda por aí, o bem não apenas 
observa, mas também avisa. A ética que queremos precisaria ser orgânica e ter voz, seríamos diferentes, tão natural e selvagens quanto precisaríamos ser. Pobre filosofia!

\section{Contra-cepções}

Essa paráfrase, no mais rigoroso estilo de heideggeriano ${ }^{2}$, incorpora o conceito confuso da ética que adotamos. Ética como virtude da alma, bem como uma mistura brilhante de inteligência e prazer, Platão (apud Châtelet, 1981) inspira uma legião de pensadores a compreender a confusa e sempre extemporânea forma metafísica de ética. Aristóteles (apud Châtelet, 1981), a felicidade, o bem humano como atividade da alma conforme à virtude, a ética é a busca da vida perfeita. Daí, as derivações metafísicas e doutrinárias espelham pela cultura ocidental afora como determinismo de uma natutreza necessária ao homem, deduzindo de tal natureza o fim a que deve ser dirigida sua conduta. Do cristianismo aos padres católicos e escolásticos, Deus é o fim último na ética religiosa, um certo apelo ao arbítrio divino. Da filosofia moderna à condição do pensar matemático, no estreito, mas já por romper conceitos de ciência e filosofia, a ética repousa nos textos modernos, empíricos, racionais, românticos, iluminístas, contemporâneos...Do bem, do justo, da virtude, na matéria e no espírito de alguma norma de conduta, nasce a estreita relação e capacidade de compreender a ética como entidade que gerencia a moral, e dela um certo relativismo axiológico. De Erasmo a Bacon, de Decartes a Spinoza, Hobbes a Lock, de Kant a Hegel, de Nietzsche a Freud, Kierkegaard a Merleau-Ponty, o espelho da ética na cultura tanto forma como deforma a arquitetura da conduta do homem. Tanto quanto podemos aceitar a ideia que os clássicos da filosofia tanto inspiraram estadistas quanto tiranos. Isto posto, tem-se uma impressão pouco original do tema. Parece vigorar a ética móvel que administra a moral relativa. Tristes tempos!

\section{Da Profissão ao profissional, da Educação Física à Ciência da Motricidade: e a prática corporal qual é a sua ética?}

Vimos destaques do pensamento sobre ética e filosofia que inspira originalidade de sentidos quanto a expressão e o significado para a cultura. Portanto, ética será sempre ética, não importa a esfera que seu conceito representa. Da sua concepção original’ as suas mais diferentes prerrogativas metafísicas, dialética, mítica, mística, ..., haverá sempre na pauta da cultura dos homens uma representação única como regra: na conduta, o bep̣, na sociedade o justo, no homem a consciência. Generalidades à parte, no confronto do homem consigo mesmo, não há como escapar de si mesmo. Já dizia o mais puro dos homens ocidentais "conheça a si mesmo", a partir daí ser humano algum escapou da perseguição do inconsciente. Lições mal aprendidas, pode-se dizer!

Contudo, em toda natureza que incorpora o espírito humano para inferir em seu próprio mundo, a questão corporal parece ser o viés sem retorno. A natureza mais profunda, o sentido prático mais expressivo, a concepção de ser mais significativa, por acaso ou necessidade, está representada pelo ser humano corporal e motor. Em sua dinâmica além das instituições da cultura,

${ }^{2} \mathrm{O}$ sentido dado por Heidegger e, Ser e Tempo. Palavra como forma de expressão e rigor interpretativo.

Revista Kinesis, Santa Maria, $N^{o}$ Especial, p. 56-154, nov. 2001 
repousa no organismo a ética imanente: organismo. Dele nada escapa, por mais espiritual que possa ser uma análise, a presença corporal é humana por excelência. A totalidade é osso (D'Hondt, 1966) não menos rigoroso, o corpo é a extensão do mundo (Merleau-Ponty, 1998), uma reflexão pré filosófica poderíamos dizer, muita além do apenas racional.

Ora, se para um pensador o corpo surge com mais que razão, para um fazedor, é. Isso mesmo, um fazedor! Talvez não haja na literatura intelectual do ocidente um fazedor de coisas assim tão explicitamente, mas certamente há na cultura de qualquer entidade viva no universo, aquela criatura que $f a z$, que é. Enquanto ser cultural toda programação comportamental demonstra ser o raciocínio lógico e a linguagem inatas, com isso demonstra Chomsky (1986), uma filogenia no mínimo interessante até para aqueles espiritualistas mais fervorosos. A ética por si mesma, não poderia derivar dessa mesma filogenia? $\mathrm{Na}$ prática, todos os comportamentos humanos atualmente "permitidos" pelos membros de uma sociedade ficam sujeitos a uma ritualização considerável, qual seja, a referência ao indivíduo com "boa conduta", boa postura, equilíbrio, flexível, forte... . Metáforas à parte, a corporeidade humana incorpora a humanidade do homem na mesma intensidade e proporção. O ser corporal se corporeidade, na mesma medida do ser humano na sua humanidade, daí a significação espontânea da motricidade. A quem ou a quantos se deve a responsabilidade de gerenciar uma ética da motricidade, ou das práticas corporais? A camisa de força imposta pelo triunfo do marketing, gerou proprietários da corporeidade alheia, onde o padrão da forma supera a valorização do $e u$. Nessa simplicidade filosófica, romântica talvez, a camisa de força da civilização em que ficou submetido o organismo humano, se estreita cada vez mais. Imploramos por uma saúde e beleza incondicional, contudo falseamos a ética existêncial e corporal. Essa anti-ética obscura gera a ética absurda. De um lado deixamos de fazer educação física de outro esquecemos a prática cultural, adotamos uma motricidade préfabricada, descartável e discursiva... Essa impostura ética da industria da ginástica, das vitaminas, das máquinas de modelar, dos cosméticos, e da moda, inspira uma legião de profissionais onde cada qual conta com sua própria ética, sua própria magestade ginástica.

Nos últimos vinte $\operatorname{anos}^{3}$ de educação física, a condição primária de credenciar a área como fenômeno acadêmico e profissional esterilizou a prática. Uma legião de pensadores faz a educação física do discurso, com suas inteligências formam a tautologia organizada: o conhecimento tal. Entregam-se à meditação burocrática, submetendo-se, como foi em todas as outras esferas do conhecimento, a obrigação de se mostrar a todo instante a competência tardia.

Vemos uma certa ética repleta de vaidade repentina em cada artigo escrito, em cada pedaço de filosofia ou ciência que se cria particularmente. Essa progressiva organização de pensadores, parece ter excluído aqueles que sustentam suas produçōes. Aqueles que vivem nas/ das quadras escolares, nos pátios, nos campos e centros de treinamentos, nos palcos, nas salas de academias ainda reina muito entusiasmo e alegria e pốuco conhecimento acadêmico. A reclamação dos malatendidos no sentido mais prático da vida, aqueles que fazem, por assim dizer, ainda reclamam: na prática a teoria deve ser outra!. Como tal necessidade ainda não foi suprida pois, em cada incubadora de conhecimento nos corredores acadêmicos, cultiva-se métodos não ciência; pensa-se mais em cada vaidade ressentida, pouca filosofia, nasce assim a impostura intelectual tornando-se difícil elogiar uma ética das práticas corporais.

\footnotetext{
${ }^{3}$ Tomando como base o discurso de professores de educação física titulados e credenciados a discursar com muita competência sobre o tema em obras como Solange C.E. Passos (org): Educação Física na Universidade. Brasília-MEC, Editora UnB, 1988 e Educação Física e Esportes na Universidade Revista Brasileira de Ciências do Esporte, Florianópolis, Set/1998.
}

Revista Kinesis, Santa Maria, No Especial, p. 57-154, nov. 2001 


\section{Ética e corporeidade: o suporte de signos}

Seria o corpo humano uma espécie de porta-gesto de uma sociedade? Face a impressão da vida social instituídas por valores e comportamentos pré-determinados pelo repertórios de signos nos faz crer numa massa de modelar à qual cada sociedade imprime formas segundo suas próprias disposições: formas nas quais a sociedade projeta a fisionomia do seu próprio espírito.(Rodrigues, 1986). Diz o autor dos ritos propiciatórios das marcas tribais, das mutilações sagradas de etnias religiosas, até a compleição atlética do ser corporal contemporâneo, reproduz uma estética da vida social. Pode-se dizer que não há sociedade que não inter-fira na forma do corpo humano. Na ausência de uma ética de si mesmo, a impostura social e de poder sobre os homens e mulheres, constróem verdadeiras sugestões intelectuais; de cirurgia, regimes e dietas, às infinitas categorias de ginásticas e exercícios que generalizam uma certa produtividade orgânica incrementando sua saúde e vitalidade. Lançar mão desses recursos parece ser quase a única maneira de se a aproximarem do ideal estético corporal que a sociedade define, dissimulando ou atenuando particularidades de sua aparência, reforça o autor. Aqui podemos compreender o distanciamento ético da relação primordial da corporeidade enquanto entidade. Intervenção cirúrgica foi antes de tudo arte médica, hoje é recuperação; dieta e alimentação sempre foram ritos, atos simbólicos e princípio de sobrevivência, hoje atividade instrumental; ginástica e exercícios físicos compunham sitius, altius, fortius, hoje atividade compensatória com uma fisiologia cada vez mais "fisiológica", uma anatomia cada vez mais "anatônica"...

Os códigos que expressam a corporeidade enquanto entidade, expressam com isso um vocabulário sociológico e não menos político. Todavia corpo é sempre representação da sociedade não há processo exclusivamente biológico do corpo, portanto toda ética sobre o corpo induz-nos a pontuar o ser humano como ser corporal. Não podemos codificar o corpo em partes, e sim um fato "total" onde cada parte depende da totalidade para extrair seu sentido. Uma ética expressaria aqui não apenas "órgãos" e "funções", ma também "instituições e "papeis". Assim, ante a ética que dispomos como recurso natural e de consciência para reerguer o ser corporal e motor que estamos buscando, com as práticas corporais ou mesmo um sentido para educação física que incrementa uma prática inusitada, exclusiva e de competência devemos reexaminar a cultura do homem em sua totalidade ontológica. Pois, a era do corpo em discussão ou do corpo em recuperação nos nosso dias não é o primeiro capítulo da história e muito provavelmente não será o último.

Nos comportamentos motores primordiais repousa a amalganha de fala e de gestos que indicavam sempre na direção do real, do fundamental, do necessáriđ o corpo com entidade e as práticas corporais como processo qu maneira de ser-estar no mundo. Só assim nos tornaremos entidades motoras imanentes à motricidade legítima, onde o sentido prático se faz como consciência natural, viva, concreta, palpável. Haverá com isso conhecedores, habilidosos e fortes. Não será necessário práticas "alternativas" pois da natureza humana se extrai um conteúdo motor que se guia por si mesmo. Em cada ato há seu ator, em cada gesto há seu gestor, em cada prática seu exercitador. Haveremos de ser o transmissor e praticante de uma ginástica intuitiva muito antes de processos e métodos de aprendizagem. Visto pela cultura, pela ética em si mesmo, a contragosto de modelos pedagógicos, veremos que toda atividade é consciência e que atividade física retornará ao seio das cavernas, só assim poderá ser dito qúe a motricidade é inerente ao ser humano.

Revista Kinesis, Santa Maria, $N^{o}$ Especial, p. 58-154, nov. 2001 


\section{Ética, representação e competência}

Para uma compreensão legítima do conceito de ética seria interessante retornar às coisas mesmas do homem. Assim, com a condição humana em primeiro plano, além do bem e do mal, o mito do eterno retorno parece ser a única inspiração que poderia fazer e dar sentido ético por tudo aquilo que chamamos educação física. Práticas corporais são compatíveis com vitalidade orgânica e consciência intelectual, além do que, o fenômenos das estruturas do movimento humano que compõem ação muscular, cognição e afetividade como demonstra Wallon (1970), MerleauPonty (s/d), Piaget (1978), podendo dizer que estes três expoentes da filo-ontogenia humana imprimiram a única e talvez mais recôndita observação de que ao homem e do homem são $e$ estão as mais infinitas categorias de motricidade que a existência pode expressar. Desde então, não há sequer há uma só ideologia, condição política, ciência ou filosofia que possa ser credenciada a tornar-se a primeira entidade proprietária da condição motora do homem. Assim, nasce aí a primeira e única ética de representação. Ao homem é dada a condição de se mover para sua sobrevivência. Tudo o mais é mera devoção particular, competição de egos, invenções de última hora. A condição legítima de estabelecer limites para uma conduta ética sobre as práticas corporais, escapam dos discursos mais inteligentes e coerentes. Essa condição vem consigo mesma uma reflexão que algum semi-deus já previa há dois mil anos virão aqueles que vos enganarás. Religiosidades à parte, resta a reflexão.

A redescoberta da educação física virá certamente por uma ética além da burocracia e dos gabinetes, virá certamente como um avalanche fora do expediente das inteligências de plantão. É assim que estamos assistindo o volume e a intensidade do organismo humano dentro do mundo contemporâneo. Não há espaço para outra propaganda senão aquela onde reina a corporeidade absoluta, dentro dela um ser humano desprotegido de significados, uma espécie de cárcere do $e u$. As educações físicas pelo montante intelectual que se inicia nos anos sessenta, num classicismo internacional e nacional com inspirações acadêmicas não conseguiram redescobrir a prática original. A inspiração em doze cavalar dos primeiros mestres e doutoras, parecem terem fugido das quadras dos campos, das piscinas, dos pátios, das pistas, dos gramados, das esquinas, das ruas... . E como toda corporeidade é absoluta e humana por excelência, parece que o pensamento se tornou nefasto, a emoção coisa banal, e o organismo objeto de compra e venda. No rigor do tempo, pensamos e deixamos de fazer. Criamos nossas obras primas e delas extraímos nossas concepções sobre educação física e as práticas corporais ${ }^{4}$. Pressionados pelo furor intelectual da produção em série dos conhecimentos agarramos as ideologias e ą ciências disponível, assim começamos a morrer e a deixar incerto ou sem rumo o sentido da prática que somos. Como recurso foi inventada a interdisciplinaridade, ou a minha interdisciplinaridade. Aquela, onde a universalidade de idéias faz o horror e o escatológico a coisá nova e interessante.

\section{A ética móvel}

"O mercador só faz bons negócios porque a mocidade ama o prazer; o lavrador lucra quando o trigo é caro; o arquiteto, quando a casa cai em ruínas; os oficiais de justiça com

\footnotetext{
${ }^{4}$ Refiro-me aos trabalhos publicados no Brasil e no exterior apartir da década de oitenta. Livros de Lamartine, Go Tani, Walter Brach, Mauro Betti, Joâo Batista, Celi Taffarel, Faria Jr, Lino Castelani, João Paulo Medina, entre muitos...sobre o tema na estrutura dos conceitos sobre Educação Física.
} 
os processos e disputas dos homens; os ministros da religião tiram honra e proveito de nossa morte e das fraquezas de que nos devemos redimir; nenhum médico, como diz Filêmon, se alegra em ver seus próprios amigos com saúde; nem o soldado seu país em paz com os povos vizinhos. Assim tudo. E o que é pior, quem se analise a si mesmo verá no fundo do coração que a maioria dos seus desejos só nascem e se alimentam em detrimento de outro. Em se meditando a propósito, percebe-se que a natureza não foge, nisso, a seu princípio essencial, pois temos os físicos naturalistas como testemunhas, que toda coisa nasce, se desenvolve e cresce em consequência da alteração e corrupção da outra. (Montaigne, 1987, p. 178).

Num primeiro momento após essa leitura deixa transparecer uma crônica de algum colunista político da imprensa contemporânea. Porém na clareza e simplicidade e atualidade do tema nos faz retornar ao século XVI entre 1553 e 1592, e aqui se revela a realidade humana que se eterniza. Neste texto de vemos a revelação da natureza humana e parece que dela dificilmente nos desprenderemos. A rigor, a conduta dos homens transparece no furor das sua necessidade de poder muito antes da necessidade de viver. Se uma condição prévia para que possamos gerenciar a vida dos outros, diria Monteigne hoje, devemos ter o cuidado de gerenciar a própria primeiro. Daí a experiência que nos escapa, ...ainda não nos conhecemos eis a ética que nos falta. Dadas as devidas extensões da cultura, em cada profissão que visamos consumar, antes de tudo visamos lucrar. Parece que a essa ética é incompatível com a espécie, assim como com o orgasmo é incompatível com o santo.

Seriam as práticas corporais uma resposta cultural daquilo que o homem deixou de fazer consigo mesmo durante quase vinte e um séculos? As práticas corporais são uma resposta ontológica ou um aviso de que corpo humano é o próprio ser humano? Temos ou somos entidades corporais e de significação e representação? Aquele que faz ginástica está no ritmo da vida e ele necessita de educação? Para que serve o conhecimento sobre as práticas corporais e sobre o sentido delas? Mudar o nome deste fenômeno chamado de prática seria uma recondução ou redescoberta do ser corporal e motor? Certamente não teremos respostas a estas perguntas tão cedo! Mas enfim, somos responsabilizados para gerar saúde e qualidade de vida, temos a obrigação de responder culturalmente pelo ambiente esportivo, ginástico, lúdico, expressivo, terapêutico, enfim somos uma entidade, porém não temos certificado de propriedade de pessoas.

Estamos como práticos que somos aguardando o momento de termos o acesso a uma cultura da motricidade humana que venha e se perpetue. Aquém desta cultura está a ciência da motricidade humana que urge como o novo e com ela uma espécie de epistemologia de plantão. O erro dessa premissa está no abandono da própria motricidade que o ḩomem é. Se por equívoco ou sede de conquista de mercado, estamos assistindo a exacerbação de tudo que se refere ao corpo humano e de motricidade geral para nos tornarmos profissionaís e de competência, restanos esperar o momento em que, para sermos solidários ou "étiEos", teremos que vender imagens, prestigiar o marketing, valorizar os sedentários, os atrofiados, os obesos, os deformados e deficientes, para que sejam nossos eternos clientes.

É fácil requerer algo para si como ciência? Difícil está sendo educar pessoas a compreender atividade física como cultura. Subtrair a má consciência de atividade física é sinônimo de sofrimento e obrigação. Seguindo Montaigne e toda uma lógica do pensamento ético do ocidente dos pré-socráticos à Escola de Frankfurt o objetivo é o homem emtodas as suas dimensões. Disse alguém bem avisado "não há ciência que não seja humana". Diz-se, há muita motricidade humana que não cabe no limitado espaço da ciência!

Revista Kinesis, Santa Maria, $N^{\circ}$ Especial, p. 60-154, nov. 2001 


\section{Ética, um elogio ao conceito de prática}

Em busca do tempo perdido... (...)...onde estará? Assim Proust expl. rc no último volume de sua obra clássica $\mathbf{O}$ tempo redescoberto, na obstinada busca e sondagem da memória de sua paixões, lugares, emoções mais nítidas, fazendo com a existência faça sentido, reerguendo ruínas da alma, na plenitude da sua vida. Nessa responsabilidade consigo mesmo, o autor dá uma lição de coragem de recriar sua própria história. Assim seria, ou deveria ser a busca daquilo que queremos sublinhar como identidade. Essa seria uma lição de prudência e rigor ético, a responsabilidade que o tempo vivido indicou não está perdida.

Na Revista Brasileira de Ciências do Esporte de setembro de 1999 vimos alguns consagrados autores sobre o tema Educação Física: Especial 20 anos de CBCE(op. cit). Um relato que mostra a diversidade sem nexo. Cada autor, reencontra seus antigos escritos e ampliam seu argumentos numa escultura intelectual devota a si mesmo. No entanto, às vistas do que está expresso na cultura contemporânea, na diversidade de idéias e no engodo intelectual onde se encontra a Educação Física, parece-nos realmente uma nau sem rumo. Não nos falta ideias, falta-nos o ajuste delas sem perdermos de vista a diversidade história, filosófica, científica e artística. Para tal é preciso reflexão e coerência, sobretudo nos nossos dias. Já conseguimos escrever e arriscar um discurso do tipo práticas corporais e modernidade. Um alívio intelectual ao glossário antigo sobre corporeidade e motricidade humana que ainda não compreendido, mas que se esvaziou pela incredulidade dos mestres e doutores num ser humano corporal e motor por excelência. Ora se Nietzche, Proust, Baudelaire, Rimbaud sobrevivem às flutuações da moda, devem isso à gratuidade de sua crueldade, à sua cirurgia demoníaca. O que faz durar uma obra, o que a impede de envelhecer é a sua ferocidade. Por onde andam os nossos escritores da Educação Física? Sejamos suficientemente ingênuos, para colocar a Educação Física numa distância tal, onde sequer pudermos observar o tamanho da cultura que ela significa. Talvez veremos não um ciência da motricidade humana, mas a poética da motricidade humana. Recurso ilusório: ela poderá fazer com que autores de livros dancem, e o vexame poderá ser maior.

\section{A lições que aprendemos}

História é implacável!

Numa época em que toda a saúde será privilegiada, onde a vida pode chegar aos cem anos, as práticas corporais estão em atividade como está toda prodútividade de uma indústria. O resultado esperado diante da insistência dos exercício indicffá o resultado legal, lucro certo. $\mathrm{O}$ sistema circulatório fará menção aos exercícios localizados e estes farão parte da estética padrão. $\mathrm{Na}$ humanidade ginástica desenvolvida, já exercitamos a falta de graça em se mover por algum motivo; a preguiça, agora sim é pecado mortal. Com alguma sutileza da indústria cultural da motricidade, virá em breve a produção da atividade física em série.

\section{A aula...}

No começo era aula, hoje atendimento, antes eram alunos, hoje clientes... 
A primeira força que as práticas corporais induzem o ser humano a executar é sua capacidade de deslocar algo real, assim é uma ação por inteira. Esse real é representável na cultura. Do primata ao executivo, a condição motora original expressa o fazer. Não há como escapar de uma cultura da motricidade humana. A aula será sempre uma lição a ser dada pela necessidade humana de estar sempre em movimento. Mudar o nome, não funciona sem mudar o todo. Que uma atividade física qualquer não reprima a outra, pois em cada títulos novo gerado no poder de indução do mercado, faz a redenção do ato motor mais primitivo. Depois desse passo, vem a aula teórica, depois a aula virtual. Daí a atrofia do músculo e depois, a atrofia do verbo.

\section{A mutação...}

Revemos constantemente a mentalidade da espécie. Em cada gesto motor há uma fala incandescente, é a matéria humana em movimento. É a praxis ainda por vir, é o sentido espontâneo do entrecruzar de ações do homem-mundo como sua natureza mais própria. A praxis não é dirigida ela é. Há uma lógica no decurso das coisas éticas que exploram essa motricidade humana que ainda não sabemos o que é essa lógica que repousa no sentido mais humano da palavra mover, imanente ao acontecer como um dado fenomenológico. A mudança de direção por onde caminham as verdadeiras concepções sobre esse tema - uso do corpo - está na cultura onde cada ser humano será indiciado por si mesmo a fazer de sua corporeidade o si mesmo vivo. Toda nomenclatura é ilusão. Ninguém é maniqueu perante si mesmo. Movem-se por si mesmos, perante a motricidade que é sua existência, porque o ato motor é em si imanente ao ser. Portanto, toda ciência, filosofia, arte, religião, sem a ética da ação servirão apenas como enteparos ou prelúdio da morte do ser corporal e motor. Mude, e haja como quem pratica a ética da motricidade humana.

\section{Referências bibliográficas}

BERGSON, H., - As duas fontes da moral e da religião. Rio da Janeiro: Zahar, 1978.

CASSIRER, C., - Filosofia de las formas simbólicas. México: Fondo de Cultura Económica, 1976.

CHÂTELET, F., - História da filosofia: a filosofia de Platão a São Tomás de Aquino. Lisboa: Don Quixote, 1981.

CHOMSKY, N., - Regra e representação. Petrópolis: Vozes; 1986.

DOUGLAS, M., - Pureza e perigo. São paulo: Perspectiva, 1966.

LEENHARDT, M., - Gens de la grande terre. Paris, P.U.F., 1967.

LÉVY-BRUHL, L., - La mentalié primitive. Paris, Alcan, 1966.

LÉVY-STARUSS, C., - O pensamento selvagem. São Paulo: Nacional, 1976.

MERLEAU-PONTY, M., - Fenomenologia da percepção. São Paulo: Martins Fontes, 1998.

MERLEAU-PONTY, M., - La structure du comportament. Paris, P.U.F.

MONTAIGNE, M., E., - Ensaios 1. Brasília, Editora UnB, 1987.

PIAGET, J., - A formação do símbolo na criança. Rio de Janeiro: Zahar, 1978.

Revista Kinesis, Santa Maria, $N^{\circ}$ Especial, p. 62-154, nov. 2001 
RODRIGUES, J.,C., - O tabu do corpo. Petrópolis: Vozes, 1986.

WALLON, H., - De l'act à la pensée. Paris: Flammarion, 1970.

\title{
The corporal practice in view of the discouses' ethic
}

\begin{abstract}
The corporal practices in the contemporary world appear as the most expressive way of the health and beauty culture. The culture of being fit arrives without warning, as a type of necessity that became fashion. We have seen that the culture of men has always praised that vital necessity of exercises, of corporal practices, and gymnastics. Those physical activity that at the beginning were supposed to be a natural and surviving ethic nowadays are being denominated in a practical nomenclature as though they were a recent invention to rescue man from indolence and the imposition of confort. To manage this unusual competence, we change a natural ethic by the discourse ethic. We are no longer corporal and practical but we became verbal and theoretical. The return to being corporal and motor requires an ethic in view of the discourse.
\end{abstract}

Keywords: Cultural practices; health, beauty 